\title{
The English language and the mass media as tools for sustainable development in multilingual nations
}

\author{
Dare Owolabi ${ }^{1}$, Charles Ikechukwu Nnaji ${ }^{2}$ \\ ${ }^{1}$ Department of English \& Literary Studies, Ekiti State University, Ado Ekiti, Nigeria \\ ${ }^{2}$ Department of Linguistics \& Nigerian Languages, University of Ilorin, Nigeria
}

Email address:

dareowo2006@yahoo.com(D. Owolabi)

To cite this article:

Dare Owolabi, Charles Ikechukwu Nnaji. The English Language and the Mass Media as Tools for Sustainable Development in Multilingual Nations. International Journal of Language and Linguistics. Vol. 1, No. 4, 2013, pp. 124-130.

doi: $10.11648 /$ j.ijl1.20130104.16

\begin{abstract}
In many multilingual nations of the world, the multiplicity of indigenous languages and cultures makes the choice of a national language for the purpose of sustainable development difficult. This paper considers the media as major sources and vehicles for development through the choice and use of appropriate language. The English language, which has transformed from its initial status of a foreign language (EFL), has since assumed the status of a second language (ESL) in many former British colonies, of which Nigeria is one, and so fits the bill as the language of wider communication (LWC). This paper shows how English can be used effectively in the mass media of communications to galvanize the populace into participating in national development, through the adoption of a level of language intelligible to the majority of the people who are consumers of mass media products through reading information as news published in the mass media. The paper considers English as used in many developing multilingual nations of the world as ideal for the purpose of mass communication for sutainable national development. Without an indigenous language as a vehicle for national integration and development in many developing multilingual nations, the one language available which is English, can be properly adopted and domesticated in the various mass media of communications to achieve national integration and development in a mutually intelligible form among all consumers of mass media products from across the various ethnic divides. The paper believes the English to be used is not the one that appeals to the Queen of England or to native speakers, but alienates the people for whom it is written. It should rather be the domesticated version of the English language that is simple enough but not a representation of linguistic errors. That version of English should reflect the local nuances of the environment that the language has found itself, since we can only speak the English that we can naturally speak.
\end{abstract}

Keywords: The English Language, The Mass Media, Sustainable Development, Multilingual Nations

\section{Introduction}

English, undoubtedly, continues to enjoy the international status of a world language, being the language most widely spoken, especially outside its place of origin. This is unlike the Mandarin Chinese, which though has the largest number of speakers in the world, has them restricted mainly to China. Ukoyen (2005:34) says "One look at the map of the world reveals that English now exists in every strategic corner of the globe, either as a mother tongue or as an official or second language". It is on record that more than half of the world's scientific literature is in the English language (Ogunkeye, 2004) and currently the major language of the internet. The language "functions across the world as the language of power and of inclusion and exclusion in participation in global activities" (Egwuogu, 2011: 31). English, although a colonial heritage, in many non-native environments, especially where British colonial masters once had one form of contact or the other, now has a major influence on the immediate environment, and, in most cases, dominating the linguistic terrain. In Nigeria, for example, despite the non-indigenous nature of the language in the nation's linguistic family, it has taken root as a second language from its initial position of a foreign language. The continued use of English in most of Nigeria's linguistic domains guarantees its status as a second language for a long time to come. In Egya's (2009:3) opinion, "the...language came to us through colonialism but, like the colonial religion, it has grown beyond being a mere vestige of colonialism. It is part of our lives" in Nigeria as 
it is in many developing nations of the world. Its use is not limited unlike some other foreign languages which have their use restricted either to the classroom or diplomatic circles. In the case of English, it is a language learnt and extensively used in addition to the various mother tongues in Nigeria (Ogunsiji, 2004). The dominance of the English language in Nigeria is evident in its superimposition on Nigeria's numerous indigenous languages (Akeredolu-Ale \& Alimi, 2002) as well as being part and parcel of Nigeria's political life (Joshua, 2002). It is the language of governance and administration at the national level and increasingly becoming the same at the state levels nationwide. The laws of the country are coded and administered in English wth occasional translations into some of the indigenous languages.

\section{Man, Language and Development}

Considering man's gregarious nature, language remains an indispensable tool, as a means of development and social cohesion, and in the current era of global information technology, it plays a major role, because no technological innovation is conceived in abstraction, that is, without the input of one language or the other (Dalha, 2005, Bashorun, 2011). Development makes life worth the while, as it is a positive change or improvement in people's living standard (Mohammed, 2003). Mbaya \& Namadi (2004), citing World Commission on Environment and Development (WCED), consider economic and social development as that which meets the needs of the current generation without jeopardizing the interest of future generations in meeting their own needs. This is made possible because man's language faculty, a cognitive divide between him and other primates, helps him communicate with others in languages that are mutually intelligible. The case of the Tower of Babel in the Scriptures demonstrates how unity through language can bring about development.

Most developed nations of the world are not bedeviled by linguistic plurality, which is the bane of development in many multilingual third world nations, such as Nigeria. Not only that, many inter-tribal strives in the world have been traced to multiplicity of languages, since cultural differences are accentuated and reinforced by linguistic differences (Age, et al, 2007). Where multilingualism exists, a lingual franca becomes imperative, not only as a Language of Wider Communication (LWC), but mainly as a unifying factor. English is the only unifying tongue among the myraids of languages in Nigeria.

The need for information and its dissemination on a wider basis has always been evident, even from man's primordial state, because information, according to Momodu (2001:30), citing World Book Encyclopedia is "a data value in decision making which acts as the live wire of any organization". Earlier, Banjo and Unoh (1976: 62) have expressed the belief that "communication is a necessary part of social cohesion at whatever evolutionary level it occurs...". This necessitated the use of town crying and other ingenious local modes of information dissemination to the masses of the people in primitive cultures. The modern age has seen a number of methods in disseminating information to wide and disparate audiences through the modern mass media. The mass media, according to Akinfeleye (1988), cited by Popoola, (2003) comprise the newspapers, magazines, newsletters, the radio, television, cinematography and film, and all these forms of mass media of communication have roles to play in national development. For example, Obiozor, et al (1999) identify some notable roles of the media towards national development, and these include the provision of instrument for opinion formation and change through the capacity to have information transmitted and exchanged between the government and the governed. Also, in their interpretive and analytical capacities, the media help direct the minds of the audience on how to think about issues and events. Dominick (2009) has correctly observed that "as media continue to evolve, several trends are already apparent: (1) audience segmentation, (2) convergence, (3) increased audience control, (4) multiple platforms, (5) user-generated content, and (6) mobile media." All these roles are performed through the medium of one language or the other, and considering the multi-tribal and multi-lingual nature of Nigeria, the English language is favored for these roles, over and above the indigenous languages for some obvious reasons.

Exposure is required for development to take place, and language can restrict or widen exposure. Since language is intricately tied to culture, a language can only express what exists in its culture and to which its speakers are exposed. Although this view of linguistic determinism (the SapirWhorf hypothesis), that "language determines how we perceive and think about the world" has received knocks in recent times, we still cannot completely run away from the fact that one is limited in exposure to what language spoken can access. This does not detract from the fact that no language is incapable of being used by its speakers to express their world view, their own way. However, for one to move above the limitation of culture restricted exposure and development, especially in developing multilingual nations, a non-restrictive linguistic code which the English language readily provides is needed. With an estimated 516 languages, each no less significant in its community (Raymond G., 2005), any attempt to select one of them is bound to meet with resistance from the users of other languages. This has necessitated the National Policy on Education, in its various versions, to recommend Hausa, Igbo and Yoruba as major languages to be studied in schools throughout the country. The provision requires a student to choose and study another indigenous language other than his/her mother tongue These are three of the many languages in Nigeria that are considered predominant and spoken in the major ethnic enclaves in the country. This policy has remained what it is, a policy, without any commitment to ensure its implementation up till now that it is moribund. This is where English has readily come in as 
the linguistic bridge across the mucky waters of Babel of voices in many multilingual nations. It has been observed that, "As a window on the world, English is looked upon as the best means to achieving economic, social and political success" (Svartvik \& Leech, 2006: 7).

\section{English in the World}

English is one language that has travelled round the world and now has almost as many speakers as its native speakers; a feat that is unparalelled in the history of any language in the world. That is not all, "The language is increasingly growing in strengths, pushing other world languages backward in the global space, opening new frontiers" (Egya, 2008/2009: 35). It is now spoken in circles, according to Kachru, as follows:

1. The Inner Circle comprising people who speak the language as first language (EL1);

2. The Outer Circle comprising users where the language assumes the status of official language and is used as a second language (ESL);

3. The Expanding Circle comprising of users who now find global relevance and advantage in English, and the language is learnt as a foreign language (EFL).

Similarly, Ogbulogo (2011) refers to English as spoken in layers as follows:

a. Inner Core (First Language Users);

b. Outer Core (Second Language Users);

c. Expanding Core (Foreign Language or International Language Speakers).

Information, doubtless, is a sine qua non of development in any society, even in the animal kingdom, and the media outfits are best strategically placed to help ensure this through the dissemination of information in an acceptable language and in an intelligible usage. Affirming this, the Holy Scriptures say '....if the trumpet gives an uncertain sound, who shall prepare himself for the battle?' (I Corinthians 14: 8). By the same token, if those who are to disseminate comprehensible development messages to the people give uncertain messages by inappropriate or complex use of language, especially when the language is not indigenous, who shall understand what is communicated and then prepare for participation in sustainable national development? Mohammed (2003: 646) puts it more succinctly thus: "since it is through the mass media that people get to know of new inventions in science and technology, then mass communicators need to package the message effectively for the ultimate users". He goes further to say that if the English language has to be used; it must be simplified for the average person to read, in line with Defoe's idea of language of mass communication as cited by Ashe (1972). Hicks (1998:1) concludes the matter when he advises journalists to write for their readers using a clear form of English by avoiding jargon, slang, pomposity, academic complexity and obscurity. An acceptable language, expressed in clear and unambiguous manner, among other factors, is essential to mobilize people and engender development in non-monolingual nations.

Development puts the present world on a higher pedestal than the primitive society and makes it worth living in. Opubor (1986:184) paraphrasing Dudley Sears, a British economist says "development involves the creation of opportunities for the realization of human potential". Development is guaranteed when the mass media, through an acceptable language, play their roles as collectors, disseminators and promoters of ideas and as mobilizers of opinions, enlightening the people on their rights, duties and obligations in the society (MAMSER, 1987). Information is an essential ingredient in a nation's socio-economic development (Yunuba, 2004), as it helps to change people's orientation and attitude. It is an indispensable element that enhances any meaningful development (Ibagere, 2002). The concept of development, it should be noted, goes beyond fiscal terms or modernization and urbanization, but "encompasses a comprehensive phenomenon that comprises improvement in the totality of a people's life" (Age, et al 2007: 199). It is

the optimization of the natural and human resources of a nation for the fostering of political unity, for the efficient production and distribution of goods and services, for the efficient management of the production system and for the enhancement of the social and economic well being of the people (Bashorun, 2011: 40).

It is common among economists, political scientists, sociologists and other scholars to use Gross National Product (GNP) and Literacy Rate as indices for measuring national development with a noticeable correlation between high per capita income and high literacy rate as yardsticks for national development (Age, et al 2007:200). What all these boil down to is that there must be noticeable positive change in the total outlook of individuals and the society at large. The mass media of communication, in their various forms, have a role to play in ensuring this by motivating the people and sensitizing them about recent innovations in all areas of human endeavor to enable them take necessary actions. The mass media "attract and direct attention to problems, solutions or people in ways which can favour the powerful and correlatively divert attention from rival individuals or groups" (McQuail, 1983: 90). Furthermore, they help in the development of knowledge by ensuring its growth and preservation by way of documentation. Indeed, "communication enhances group activity because without communication, co-ordination and change cannot be effected" (Yusuf \& Isah, 2001: 201). This is where appropriate language, both in choice and intelligible usage becomes germane. The English language, as the appropriate choice because of its strategic status as linguistic bridge across Nigeria's divergent languages, must be put to intelligible use by Nigerian journalists for the various categories of users of English to enable them fully appraise their messages.

The pre-eminence of the English language in the country is backed up by the constitution and the National Policy on Education (NPE), particularly for the purpose of education. 
English has the highest number of speakers amongst all the languages spoken in the country-indigenous or foreign. The press is run for profit-directly or indirectly and is number driven. Market size, econimic power, literacy level etc. all relate to their individual real value and to population, and Nigeria is simply the most populated African nation. Deriving from that is the fact that English has about the largest market in Africa in Nigeia. This fact has been noted by Ukoyen (2005: 37), when he avers that given Nigeria's importance in the West African sub-region; its population, growing diplomatic influence and intellectual recognition on the international scene, the country holds the key to the continued survival of the English language on the African continent, ranking with Egypt and South Africa as the three giants of Africa.

\section{The English Language Option in Developing Multilingual Nations}

Nwuneli (1986:203) expresses support for the use of the predominant local language of the target audience to create more awareness for any initiated social action; saying the obvious, that an audience prefers the local language to any high sounding English or French language. This definitely must be with reference to a segment of the society. The Nigerian society is a very heterogenous one. It has been suggested that, if the intention of journalists is to reach the people, a more accessible indigenous language is required, as a non-indigenous language tends to alienate majority of the people. Although many share this opinion that indigenous languages are ideal (Ibitoye, 2000) for mass communication, we hasten to say that the adoption of any indigenous language(s) is more likely to serve a divisive, rather than a unifying, role in multi-lingual nations, and unity is a necessary ingredient for development in any nation. In Nigeria, for example, since the amalgam, wazobia, an artificial language, hit the rock like Esperanto, its international version, the constitution recommends the use of indigenous languages, especially, the so-called big three: Hausa, Igbo and Yoruba in the national parliament when adequate arrangement can be made to that effect. But since the beginning of the second republic in 1979 till date not one session has held in any of the languages. Their use remains restricted to certain domains, even in their immediate geo-linguistic setting. Indigenous languages, when adopted in complex multilingual nations, serve limited purpose when it comes to mass communication since the use of any indigenous language serves its immediate linguistic community to the near exclusion of all others, and as such, limits exposure, hinders information spread and dwarfs ability to develop. This, therefore, necessitates the adoption of the English language, by many, for mass communication, for the purpose of sustainable development.

Vernacular news media circulate in limited environment and are used to further the course of either the founder(s) or the immediate geolinguistic community. These vernacular newspapers are very few because of the limited readership, and their existence is even more precarious because of economic problems such a venture brings upon publishers, which makes publishing in vernacular languages unattractive.

English is an irrestible language as far as development is concerned because "for any nation particularly in the $3^{\text {rd }}$ world to be relevant and derive the maximum benefit from the opportunities that abound in every area of human need, for personal advancement and national development, English is a sine qua non" (Babajide, 2002: 52). This is why English continues to hold sway as the language of development in most developing nations of the world, and even in some developed nations of Asia, where it is learnt and used as a foreign language. In linguistic parlance, however, "English has no intrinsic superiority over any other language" because "one can do anything with any language given enough time” (Banjo \& Unoh, 1976: 58).

The Nigerian press parades a number of journalists who use the English language as the medium of information dissemination. There are research indications that comprehensibility is hindered as a result of complex use of English by Nigerian journalists (Owolabi, 2007), although peculiar to the print media as the electronic media's use of English is within comprehension to stimulate the populace to participate in sustainable development. The complex use of English by print journalists in Nigeria may not be peculiar to them as Pickup (1989:5) notes that "journalists all seem to share a great delight in juggling with words" and concludes that unnatural use of words through the adoption of figurative expressions may be highly inventive and give fulfillment to journalists, it is, nonetheless, linguistically tasking on the part of readers who may not be as linguistically endowed as the writers. As observed by Nostrand, et al (nd), there is a contract between a writer and his reader, and whenever a writer forgets his reader's frame of reference, he fails to communicate. A writer should, therefore, not assume that satisfying self will satisfy readers because "no reader will make an effort to understand if the writer has not first made an effort to communicate" (Nostrand, et al, nd: 62). If people are to be actively involved in development, especially in developing multilingual nations, information must flow uninhibited because nothing happens without recourse to information except things divine (Womboh \& David, 2002).

The media, as agents of growth and development through communication, should ensure free flow of information by making new ideas for development available to majority of the populace through appropriate choice as well as a level of language that is easily comprehensible. The choice of English in Nigeria is borne out of necessity because "As it is today, we have no other language...for official and inter-ethnic communication apart from...English...The issue...is not whether we accept it or not, it is rather how we...deploy it to serve our communicative and social needs" Egya (2008/2009: 33). 
This should be in the form identified by Defoe, and cited a long time ago by Ashe (1972). It is a language style in which a man, speaking to 500 people of all common and various capacities, idiots and lunatics exempted that will be understood by them all. The extent to which print journalists in Nigeria conform to Defoe's standard of mass communication language is better imagined judging from the way many of them write? Eko (2002) alligning herself with Defoe says a good writer "avoids high-flown pompous language", going further to say that "simplicity is a basic quality of good writing". Good writing is also very essential to effective communication which, according to Onobajo (2001), is a message made available to a targeted audience that finds it comprehensible and with a positive change of attitude towards the communicated message. This type of writing helps motivate the citizenry for participation in developmental activities. This is achievable, if the advice of Oguntuase (2006:21), writing on newspaper English in Nigeria, is heeded. According to him: "Jargon...should be avoided...our newspapers and magazines should be readable and intelligible to all our readers, most of who are students...Technical terms...should be used in their proper context...In many instances, simple words or terms can do the job".

Since none of the indigenous languages is currently serving the purpose of a national language, and the English language will still continue to serve this purpose for a long time to come, second language English journalists should consider the various counsels given on good and effective writing to enable them perform their role as motivators and mobilizers of people for national development.

According to Egya (2008/2009: 33) "the English language in some of the national news broadcast on the radio and the TV is good", and within ESL users'comprehensibility, but what about our newspapers which have been so proliferated in recent times? Nigeria can now boast of about 133 in circulation, comprising 32 dailies, 83 weeklies, 4 fortnightly newspapers, 4 monthlies and 9 vernacular newspapers (Age, et al, 2007 citing Yahaya, 2003). The list is still growing with politicians swelling the number for political propaganda, and majority of them use the English language as medium of communication, but the extent of effective communication may be questionable, from the style of many of them. The electronic media do not seem to manifest this complexity in the use of the English language. The electronic media have some flexibility, especially with the ecclectic nature of their programs, a practice that is not quite possible with the print media. The flexibility offered by the electronic media puts them in strategic positions to use, not only the indigenous languages for easy comprehensibility of essential messages, but also the English language in its various forms, adopting styles that are appropriate for different groups of listeners and viewers. This is where English that reflects local idioms as used by Nigerans, comes in and should be popularised. This is English "imbued with our linguistic peculiarities, only viable within the confines of Nigeria, and it enjoys a great deal of intelligility with other Eglishes of the world" Egya (2008/2009: 33) and it is English that is simple enough for easy comprehension, and not difficult metaphors that unnecessarily task reader's brain in a society where, the demand of modern living requires a lot of running around by the people before they can make ends meet (Daramola, 2003). It is Standard Nigerian English distinct from "a wanton abuse of the English language in whatever guise" (Egya, 2008/2009:34). Whether in news reporting, editorial or feature article, this is the type of English expected, not the type that appeals to native speakers but alienates the people for whom it is written. This is the type of English that is culturally conditioned lexically and characterised by transliteration, a form of nativization, where L1structure is used to express ideas in L2.

Examples of Nigerian English that is capable of easy comprehensibility needed to galvanize the people into participating in sustainable development can be found in the following from some Nigerian newspapers, with Standard English equivalents in parentheses:

a When hosts begin to show the guest the hard top of the yam, it's time to leave (Quit when the ovation is loudest).

b Trousers are no symbols of wealth (The hood does not make the monk).

c Being bold is better than having juju (Virtue is bold, and goodness never fearful).

$\mathrm{d} I$ I don't even want to imagine the number of buckets of swear words and bags of curses being thrown in the man's direction right now (The volume of expletives and curses on the man is unimaginable).

e When did beheading a man become the cure for his headache? (You do not cut off your nose to spite your face).

The first three examples were actually made by an Italian who holds a British passport and has lived and worked in Nigeria since the 60's. This shows that he has realized the use of English in Nigeria to reflect the Nigerian environment. In reality, not much difference is found in the written English in Nigeria to impair intelligibility, nationally and internationally, as the syntax of English cannot be interfered with significantly without doing serious damage to meaning in the language. The so-called difference between Nigerian English and other standard English varieties is noticeable in the phonology.

\section{Conclusion}

Every nation desires development, but most often, when issues of development are discussed, leaders hardly ever give consideration to langage. This is unfortunate, because language plays a key role in development, especially when properly deployed in the mass media of communications. People's awareness must be raised to enable them partake in matters of development and the mass media of communications can help create the needed awareness 
through appropriate language choice and its proper use. This will contribute positively and meaningfully to the development of man and the society at large through the media's surveillance and interpretive roles. Without an indigenous language as a vehicle for national integration and development in many developing multilingual nations, the one language available which is English, can be properly adopted and domesticated in the various mass media of communications to achieve national integration and development in a mutually intelligible form among all consumers of mass media products from across the various ethnic divides. No doubt, an indigenous national language is considered the most ideal for sustainable national development, but where there is no acceptable indigenous national language, as is the case in Nigeria, an acceptable lingua franca will serve the purpose. In Nigeria, English remains for us a national identity, which the nation's constitution has, somehow, conferred on it. It may, therefore, sound rather hypocritical and "not very rational to reject English chauvinistically just because it is the language of a former colonial power, if it had a certain place and certain resources invested in it in the country concerned" (Banjo \& Unoh, 1976:59). The media, in developing multilingual nations, especially those colonized by the British must therefore see it as part of the colonial heritage as well as a member of our extended linguistic family and must be used in a manner that will enhance mutual intelligibility required for motivation, social integration, and sustainable national development. This can be done by giving it a national identity as it has been done in many parts of the world where English has been exported and adopted. Now Singapore has 'Singlish', Spanish English is 'Spanglish", Germlish is German's version of English, etc. In the same fashion, Nigeria can also have 'Niglish', a Nigerian version of the English language, popularized by the media, accessible to the masses and internationally intelligible to guarantee social integration and sustainable national development. There can be different versions such as "Hausglish" (Hausa+English), "Igblish" (Igbo+English) and "Yonglish" (Yoruba+English), etc to still reflect the nation's linguistic diversity. Eka (2009:9) has noted that "L2 speakers are generally known to use a local, indigenized...non-native variety but, depending upon the size of English speakers in each, they may have a large range of sub-varieties, some of which constitute approximations of near-native speech and international variation". The Nigerian varieties of English are there and should be developed and used to achieve our linguistic needs. As we all know, “...we can only speak the English that we can naturally speak...such issues are of interest and not a threat to providers of English of a standard variety" and second language English users "are in a position to be able to choose the language that best fits their target language community" (Hemmi, 2009: 7).

\section{References}

[1] Akeredolu-Ale and Alimi, M. M. (2000). Linguistic Dilemma of Second Language Learners: Implications English language Teaching. Research in African Languages and Linguistics (RALL) 6, 67-80.

[2] Age, A. I., Igbashal, A. A. and Ashi, K. (2007). Mass Media and National Development. International Journal of Language and Communication Studies 1 (1\&2) 199-207.

[3] Ashe, G. (1972). The Art of Writing Made Simple. London: W.H. Allen.

[4] Babajide, A. (2001). Language Patterns of Nigerians. In Igboanusi, H. (ed.), Language Attitude and Language Conflict in West Africa. Ibadan: Enicrowfit Publishers.

[5] Bashorun, N. O. (2011). Development and its Implications for Cultural, Technological and National Development in Nigeria. Lagos State Polytechnic Inaugural Lecture E, Series No 2, pp. 22-44.

[6] Banjo, L. Ayo \& S. O. Unoh (1976). Effective Use of English. Lagos: Thomas Nelson (Nigeria) Ltd

[7] Crozier, D. H. and Blench, R. M. (eds) (1992). An Index of Nigerian Languages. Texas: Summer Institute of Linguistics.

[8] Dalha, L. (2005). Language and Multimedia Technology: Analysis on Computer Application and the Internet. Nigeria Journal of Science, Technology and Environmental Education (NIJOSTEE) 1(1) 267-278.

[9] Daramola, I. (2003). Introduction to Mass Communication. Lagos: Rothan Press Limited

[10] Directorate for Social Mobilisation (1987). Report of the Political Bureau. Abuja: MAMSER.

[11] Dominick, J.R.(2009) The Dynamics of Mass Communication: Media in the Digital Age 10th edition Boston: McGraw-Hill.

[12] Egwuogu, C. B. (2011). Teachers' Perception of the Continued Use of English as the Language of Instruction in Nigerian Schools. Journal of the Nigeria English Studies Association, 14 (1), 30-45.

[13] Egya, Sule E. (2008/2009). Crippled Idiom: The English Language in Nigeria in the Twenty-First Century. English Language Teaching Today (ELTT) 7, 32-36.

[14] Eka, D. (2009). Phonological Structure, Variations and Innovations in Educated Spoken Nigerian English. In Adegbite Wale \& Olajide, B. (eds). English in the Nigerian Environment: Emerging Patterns and New Challenges. Lagos: Olivetree Publishing Venture.

[15] Eko E. (2002). Effective Writing. Ibadan: Heinemann Educational Books (Nigeria) PLC.

[16] Hemmi, C. (2009).Rhythmicity and diversity in global interactions. iatefl Voices, July-August, 2009. Issue 209, p.7.

[17] Hicks W. (1998). English for Journalists. $\left(2^{\text {nd }}\right.$ edn). London and New York: Rutledge.

[18] Ibagere, E. (2002). Communication and Rural Development: a Model for Developing Countries. Humanities Review Journal 2 (1) 57-67. 
[19] Ibitoye, G. (2000). National Development, Language and the Media. Work In Progress. Journal of English Department, Ahmadu Bello University, Zaria, Nigeria. 11, 93-101.

[20] Joshua A.(2002).Language, National Integration and Nigeria Federation. Humanities Review Journal 2 (1) 93-100.

[21] Mbaya, P. Y. and Namadi, B. (2004). Enforcement of Public Accountability in Public Service for Sustainable Development in Nigeria. Global Journal of Social Sciences 3 (1\&2) 11-16.

[22] McQuail, D. (1983). The influence and effects of mass media. In Curran, J, Gurevitch, M.\& Woollacott, J. (ed.). Mass communication and Society. London: Edward Arnold in association with The Open University Press.

[23] Mohammed, A. J. (2003). The Role of Communication in Technological Development. Nigeria Journal of Gender and Development 4 (1) 644-650.

[24] Momodu, M. O. (2001). Information Needs and Information Seeking Behaviour of Rice Farmers in Ekpoma town, Edo State of Nigeria. Communicate: Journal of Library and Information Science 3 (1\&2) 30-34.

[25] Nostrand, V, Knoblauch and Pettigraw (nd). The Process of Writing (2nd edition). New York: Houston Mifflin

[26] Obiozor, G. A. and Onyekwere, E. C. (1991). The Role of the Nigerian Media in the Creation of Democracy. In Uche, L.U. (ed) Mass Communication, Democracy and the Civil Society in Africa. Federal Ministry of Education: National Communication for UNESCO.

[27] Ogunkeye, O. (2004). Linguistic Acceptability and the Learner of English as a Second Language. Nigeria Journal of the Humanities 11, 106-121.

[28] Ogunsiji, A. (2004). Developing the Basic language Skills for Communicative Competence in Learners of English as a Second Language in Nigeria. Ibadan: Journal of English Studies 1, 19-34.
[29] Oguntuase, B. (2006). Newspaper English. In Mind Your Language Column. Daily Sun, Thursday, September 7, p.21.

[30] Onobajo, O. (2001). Communication Models in NonFormal Education. Humanities Review Journal 1(2) 82-88.

[31] Owolabi, Dare (2007). English Language as a Medium of Mass Communication in a Second language Situation: The Nigerian Press as an Example UNAD Studies in Language and Literature 2 (2) 57-67.

[32] Pickup, I. (1989). How 'Readable' is the French Press? Wordplay, Pun and Metaphor in L'Equipe. The British Journal of Language Teaching xxvii1(1)3-8.

[33] Popoola , I. S. (2004). The Role of the Mass Media in Reducing Political Violence: A Case Study of the Nigerian 2003 General Elections. UNILAG Journal of Politics 1 (1) $187-208$.

[34] Raymond. G.G. Jr. (ed.) (2005). Ethnologue:Languages of the World. (15th edition). Dallas, Tex: SIL International. Online Version: http://www.ethnologue.com/

[35] Svartvik, J. \& Leech, G. (2006). English One Tongue, Many Voices. Palgrave Macmillan.

[36] Ukoyen (2005). The English Language and the rest of the World. In Proceedings of the Workshop on Restoring Excellence in the Faculty of Arts. A Publication of the Faculty of Arts, University of Ado Ekiti.

[37] Womboh, B. S. H. and David, M. B. (2002). Information Science, Management and Resource Sharing. Yola: Paraclete Publishers..

[38] Yunuba, D. (2004). Nurturing Information and Communications Technologies in Africa. Humanities Review Journal 4, 11-23.

[39] Yusuf, A. \& Isah, R. (2001). Communication for Information Professional. Sabondale Journal of Technical Education 4, 20-23. 